\title{
LIBERTINAGEM COMO LINGUAGEM Refletindo as analogias
}

\section{Libertinage as Language, Reflecting the Analogies}

Francisco Verardi Bocca ${ }^{1}$

\section{Resumo}

O presente artigo tem a intenção de refletir sobre a noção de logoteta atribuída por Barthes a Sade. Para isso ele admite que a despeito da língua de Sade apresentar um caráter artificial, o que a distinguiria da linguagem natural tematizada por Saussure, não obstante, em sua formulação recorre às mesmas operações que dão constituição à linguagem natural, o que permite pensarque a noção de língua se aplica à organização da orgia, em particular, e à obra de Sade, em sentido geral. Aqui veremos que Barthes, a exemplo do que propôs Saussure, mais uma vez realiza uma extrapolação da noção de língua, que foi a princípio concebida como o objeto próprio da lingüística, a outros sistemas simbólicos não lingüísticos. Por conta disso, haveremos de investigar até que ponto a nova língua de Sade compartilha da natureza arbitrária e imotivada da língua saussuriana. Em outras palavras, a adequação do uso do conceito de língua à ordenação erótica que Sade concebe e que Barthes reconhece segundo um estatuto de linguagem. Palavras-chave: Filosofia; Linguagem; Semiologia; Literatura; Libertinagem.

1 Doutor em Filosofia pela UNICAMP, Docente do Programa de Mestrado em Filosofia da PUCPR.

E.mail: francisco.bocca@pucpr.br

Rev. Filos., v. 18 n.23, p. 53-72, jul./dez. 2006 


\section{Abstract}

This article intends to reflect about the notion of logoteta attributed by Barthes to Sade. For this he admits that spite of Sade's language presents an artificial character, what would distinguish it from the natural language focalized by Saussure, anyway, in its formularization appeals to the same operations that gives constitution to the natural language, what allows to think that the language notion is applied to the orgias 's organization, in particular, and to Sade's work, in generality meaning. Here we will see that Barthes, an example of what was proposed by Saussure, one more time carries out an overstep of the language's notion, that was at the beginning conceived as the proper linguistics' object, to other symbolic systems not linguistics. On account of this we will have to investigate till which point the new Sade's language shares of the arbitrary and imotivada nature of the saussurian language. In other words, the adequacy of the use of the language concept to the erotic ordinance that Sade conceives and that Barthes recognizes according to a language statute.

Keywords: Philosophy; Language; Semiology; Literature; Libertinism.

\section{Apresentação}

Os leitores de Sade bem como de seus comentadores certamente estão familiarizados com a recorrência com que os ensaios de Roland Barthes figuram como subsídio de análise e interpretação da obra sadeana. Com recurso aos conceitos saussurianos, motivado pela perspectiva semiológica, Barthes reconheceu no projeto literánio de Sade a construção de uma língua. Admitido isso, pretendemos apresentar seus argumentos, bem como avaliar o alcance e propriedade deles. Informamos que o tratamento dessa questão tomará por base os seguintes textos de Barthes: Sade, Fourier, Loyola, de 1971, A metáfora do olho, de 1963 e Mitologias, de 1957.

Sustentamos assim o propósito de avaliar a iniciativa de Barthes, freqüente ao longo de sua produção como semiólogo e crítico literário, de aplicar os conceitos saussurianos formulados no interior da lingüística aos demais fatos humanos, o que corresponde a realizar 0 ideal semiológico preconizado pelo próprio Saussure. O resultado desse exame deve permitir uma avaliação das possibilidades de execução desse ideal e em decorrência da verdade da máxima saussuriana que apresenta a lingüística como "o padrão geral da semiologia". 
Assim, assumindo o enfoque semiológico de Barthes em prefácio à obra Sade, Fourier, Loyola, de 1971, reproduziremos sua afirmação de que Sade é, em sua produção literária, um logoteta, isto é, um fundador de língua. Tal conceito é aqui pensado no interior da lingüística desenvolvida por Saussure, bem como da semiologia por ele concebida em seu Curso de lingüística geral, de 1915. Lembremos que Barthes ao assim proceder extrapola a noção saussuriana de língua; dizemos isso apoiados em sua própria fala. Diz ele, a respeito de Sade, que "a língua que funda não é evidentemente uma língua lingüística, uma língua de comunicação. É uma língua nova..." (1971, p. 7). Com isso ele aponta que a despeito da língua de Sade apresentar um caráter artificial, o que a distinguiria da linguagem natural tematizada por Saussure, não obstante, em sua formulação recorre às mesmas operações que dão constituição à linguagem natural, o que permite pensar que a noção de língua se aplica à organização da orgia, em particular, e à obra de Sade, em sentido geral. Aqui veremos que Barthes, a exemplo do que propôs Saussure, mais uma vez ${ }^{2}$ realiza uma extrapolação da noção de língua, que foi a princípio concebida como o objeto próprio da lingüística, a outros sistemas simbólicos não lingüísticos. Por conta disso, haveremos de investigar até que ponto a nova língua de Sade compartilha da natureza arbitrária e imotivada da língua saussuriana. Em outras palavras, a adequação do uso do conceito de língua à ordenação erótica que Sade concebe e que Barthes reconhece segundo um estatuto de linguagem.

\section{Sade logoteta}

Comecemos essa reflexão lembrando que Barthes declara que Sade segue, na condição de logoteta, ao menos em parte, "as vias de constituição da linguagem natural" (1971, p. 8) recorrendo a operações similares. As tais operações na elaboração dessa língua que formula e executa são: o isolamento, a articulação, a ordenação e a teatralização. Quanto à primeira operação, diz Barthes...

2 Sobre a extrapolação do uso do conceito de língua para sistemas não-lingüísticos feita por Barthes, ver Bocca, F. V., artigo Barthes, um semiólogo nômade, in Revista de Filosofia, v. 15, n. 17, 2003, Curitiba, PUCPR.

Rev. Filos., v. 18 n.23, p. 53-72, jul./dez. 2006 
...A nova língua deve surgir de um vazio material; um espaço anterior deve separá-la das outras línguas comuns, ociosas, ultrapassadas, cujo ruído poderia perturbá-la: nenhuma interferência de signos...Sade fecha os seus libertinos em lugares invioláveis (Castelo de Silling, convento de Sainte-Marie-des-Bois) (1971, p. 8).

Sobre isso, lembremos que há nas obras de Sade, muitas vezes, como em Silling, um abismo que separa o castelo que é palco da orgia da sociedade e que é aprofundado pela destruição da ponte de madeira que lhe dá acesso, interrompendo qualquer possibilidade de ligação com o mundo exterior e garantindo o isolamento e impunidade que a orgia necessita, a saber, um mundo à parte.

Mas é quanto à segunda operação, a articulação, que a analogia lingüística se torna mais pertinente uma vez que ela pressupõe a presença de signos elementares e distintos que possam ser continuamente combinados e ajustados. Na construção da noção de logoteta, Barthes afirma que "Sade distribui o gozo como as palavras de uma frase (posturas, figuras, episódios e sessões)" (1971, p. 8), sendo elas constantemente combinadas e ajustadas segundo regras gramaticais. Por conta disso denuncia em Sade a substituição da criação pela sintaxe, isto é, pela limitada composição combinatória que tais regras permitem. Adiante, isso será esclarecido quando apresentarmos a distinção que ele concebe em relação à escrita de Bataille.

A terceira operação identificada por Barthes, a ordenação, corresponde a algo superior, para além da articulação de signos elementares, atingindo uma ordem superior que chamou de métrica, que é promovida por um ordenador, um libertino que, diz ele, "sem nenhuma preeminência que não seja uma responsabilidade passageira e meramente prática efetua posturas e dirige o andamento geral da operação erótica” (1971, p. 9). Nesse caso, Barthes define a presença do libertino como aquele que tem a função de regular, mas não, adverte ele, a de "regulamentar o exercício, a sessão, a orgia, mas esse alguém não é um sujeito; regente do episódio é apenas um de seus momentos, não passa de um morfema de recção, um operador de frase" (1971, p. 9). O libertino é, nessa visão, aquele que promove e sustenta um tipo de ordem necessária para o prazer visado, alcançada por meio do rito da orgia, daí exigir um planejamento impecável. A referência a esses tipos de operações remete ao recurso de outro

Rev. Filos., v. 18 n.23, p. 53-72, jul./dez. 2006 
conceito saussuriano ${ }^{3}$, a saber, o de dupla articulação, que inclui a ordem fonemática e a monemática. Contudo, antecipemos para retomar adiante, que a aproximação se mostra limitada do ponto de vista conceitual, uma vez que o sistema fonemático que Barthes identifica na escrita sadiana, como as posturas, não corresponde ipsis literis ao da linguagem natural que é, em primeira instância, puramente regido por leis sintáticas, sem remessa a qualquer tipo de organização semântica.

Retomando, reforcemos que o que de fato Barthes atribui à terceira operação, a de ordenar, apresenta uma curiosidade em relação à aproximação com os conceitos saussurianos. Diz ele que o libertino realiza um tipo de métrica, pois "o discurso novo é dotado de um ordenador, de um mestre-de-cerimônias, de um retoricista” (1971, p. 9). Este não corresponderia, digamos desde já, a alguém que ocupasse o papel de um sujeito gramatical, uma vez que não apresenta, na evolução da orgia, nenhum tipo de privilégio. Antes, apenas comanda a ordem orgiástica, vale dizer, regula-a, aplica regras, faz cumprir deveres. De fato, nessa perspectiva, ele não regulamenta a evolução da cena criando regras $^{4}$, sujeitando os participantes à sua própria regulamentação, o que 0 aproxima da função de um regente de orquestra.

Por conta dessa condição Barthes segue apontando que Sade não é um autor, mas um formulador, também entendido como escritor. Com essa distinção opõe à noção de escritura a de estilo ${ }^{5}$. Esta oposição serve para dar finalmente apoio à introdução da quarta operação na elaboração da nova língua, a saber, o teatralizar, isso para fins de fundação completa da língua erótica. Define essa última operação como eqüivalente a "não enfeitar a representação... mas ilimitar a linguagem" (1971, p. 9), ou ainda, escaloná-la ao infinito. Nessa operação, diferentemente do que se pode chamar de estilo que apresenta um enlace com a noção de sujeito, a escritura é pensada como uma organização e escalonamento que é antes uma forma. Diz ainda Barthes, "o estilo implica uma consistência, a escritura...só conhece insistências" (1971, p. 10), uma repetição estereotipada, um pôr em cena atos insistentes. Assim, a insistên-

3 Sobre isso ver SAUSSURE, F. Curso de lingüística geral. São Paulo: Cultrix, 1915.

4 Talvez aqui a identificação às noções saussurianas de autonomia da língua, bem como de arbitrariedade do signo lingüístico ganhe algum tipo de consistência, uma vez que exclui, no exercício do discurso, a motivação do falante.

5 Sobre os conceitos estilo/ escritura e consistência/insistência, ver Roland Barthes, p. 52 em O prazer do texto, Ed. Perspectiva, 1973.

Rev. Filos., v. 18 n.23, p. 53-72, jul./dez. 2006 
cia de Sade transforma sua escritura em uma sistemática, a exemplo de um cenógrafo de uma peça que a estende ao infinito de forma insistente; infinita e ilimitada no sentido de uma repetição ou reiteração contínua.

Uma vez apresentadas as quatro operações de inspiração lingüística, passemos a refletir sobre elas. Ora, quando Barthes refere-se à clausura dos lugares sadianos, aponta sua função, a de fundar uma autarquia social, que é geradora de uma sociedade completa, um mundo à parte, organizado em um sistema, onde há uma intenção de, diz ele...

...Definir os seres por suas funções e em regulamentar a entrada em jogo dessas classes funcionais, segundo uma encenação minuciosa, mesma preocupação em organizar uma economia das paixões, em suma, harmonia e utopia. (1971, p. 21)

Enfim, uma cotidianidade infinita, regida por um código autônomo que estabelece sentidos, ou ainda, que relaciona unidades segundo regras, como estamos procurando demonstrar, à maneira de uma linguagem articulada, a exemplo da linguagem natural. Resta investigar se Barthes está plenamente autorizado a postular qualquer tipo de autonomia desse sistema, como pleiteada por Saussure, já que o rito encenado na orgia só pode ser pensado como uma forma de planejamento, o que expõe desde já a noção de indiferença e apatia atribuída ao libertino/formulador.

Dissertando sobre as operações eróticas de Sade, Barthes, postulando o conceito de linguagem articulada, diz que ele combina...

...Segundo regras precisas as ações específicas da luxúria, de maneira a fazer dessas seqüências e agrupamentos de ações uma nova "língua”, não já falada, mas agida; a língua do crime, ou novo código de amor, tão elaborado como o código cortês. (1971, p. 29)

Isso acentua a noção de ordem a que está submetida a orgia, pois ainda que a luxúria seja ilimitada não podemos deixar de atentar para uma declaração de Barthes: "para os libertinos, o projeto educativo tem amplidão maior: trata-se de chegar ao absoluto da libertinagem" (1971, p. 27) sendo que isso não se dá nunca sem uma ordem explícita ${ }^{6}$.

6 Sobre a base filosófica de Sade que, a partir dos "naturalistas modernos" postula a equivalência entre criação/destruição, crime/virtude, ordem/desordem, ver o capítulo A cifra e o corpo, in: Lições de Sade, de E. R. Moraes, Iluminuras, 2005. 
Chegamos assim à noção de código erótico que, segundo Barthes, foi pelo próprio Sade elaborado e determinado. Ele é descrito, como dito acima, na perspectiva da dupla articulação lingüística como dotado de uma unidade mínima, a postura, que é "a menor combinação que se possa imaginar, pois reúne apenas uma ação e o seu ponto corporal de aplicação; não sendo infinitas essas ações nem esses pontos...podem perfeitamente enumerar-se" (1971, p. 30). Trata-se assim da postulação de que sejam elementos ou unidades simples que podem ser, sem dificuldades, inventariadas.

Dentre esse primeiro inventário de elementos simples da postura Barthes inclui "o exame da vítima, o interrogatório, a blasfêmia etc." (1971, p. 30), além do laço de família (na forma de incesto), a posição social, a sujeira, a feiura, os estados fisiológicos etc. Assim pensados, por analogia aos fonemas da linguagem natural, os componentes ou elementos simples da postura, também pensados como formação elementar, são repetidos necessariamente como elementos de combinações superiores. Em texto anterior, A metáfora do olho, de 1963, Barthes declara que a narrativa erótica de Sade é de natureza essencialmente sintagmática, pois, diz ele...

...Dado um certo número de lugares eróticos, Sade deduz todas as figuras (ou conjunções de personagens) que podem mobilizá-los; as unidades primeiras são em número finito, pois nada é mais limitado do que o material erótico, mas são suficientemente numerosas para se prestarem a uma combinatória aparentemente infinita (os lugares eróticos combinando-se em posturas, e as posturas, em cenas), cuja profusão forma o relato sadiano. Em Sade, não há nenhum recurso a uma imaginação metafórica ou metonímica, sua erótica é simplesmente combinatória... (1963, p. 128).

Desse modo, essa primeira articulação das posturas, também chamado por Barthes em Mitologias de sistema suporte, quando combinadas proporcionam "uma unidade de nível superior" (1971, p. 30). Tal nível ou unidade superior de combinações das posturas Barthes chamou-0, como visto, de ordenação. Seu nível é justamente aquele que passa a envolver um número cada vez maior de atores e recebe, segundo o incremento de sua articulação, os nomes de figura e episódio. Temos a partir daqui o nível sintagmático da orgia, atingindo, como diz Barthes...

Rev. Filos., v. 18 n.23, p. 53-72, jul./dez. 2006 
...A maior unidade possível dessa gramática erótica: (é) a cena ou sessão. Passada a cena, encontra-se a narrativa ou a dissertação. Todas as unidades estão submetidas a regras de combinação ou de composição. Essas regras permitem facilmente uma formalização da língua erótica, análoga às "árvores" gráficas propostas pelos nossos lingüistas: seria, em suma, a árvore do crime. (1971, p. 31)

Temos assim a noção formal de uma língua erótica, posto que todas as unidades e níveis estão submetidas a regras de combinações. Chegamos com isso ao ápice da noção gramatical acerca da narrativa sadeana. Contudo, há ainda a exposição de duas regras de operação apresentadas por Barthes que permitirá desdobramentos em nossa análise. Trata-se de dois modos de pôr em movimento ou em relação as unidades mínimas, como visto, identificadas como posturas. Mencionaremos aqui apenas a primeira regra, que Barthes chamou de exaustividade. Diz ele que...

Numa "operação", é necessário que o maior número de posturas seja cumprido simultaneamente; isto implica por um lado que todos os atores presentes sejam empregados ao mesmo tempo e, se possível, no mesmo grupo ${ }^{7}$ (ou, em todo caso, em grupos que se repetem) e, por outro lado, que, em cada sujeito, todos os lugares do corpo sejam eroticamente saturados; o grupo é uma espécie de núcleo químico de que nenhuma "valência" deve ficar livre: toda sintaxe sadiana é assim busca da figura total. (1971, p. 31)

Dessa citação nos deteremos na referência à noção de valência que permite, analogicamente, uma aproximação do modo de funcionamento atômico/molecular com o da cena sadiana, onde, como dito, nada ou ninguém fica livre de contatos, além de que em ambos sistemas visase uma totalidade ou estabilidade.

Recorrendo ainda ao artigo de 1963, no qual, ao estabelecer relações comparativas entre as narrativas de Sade e de Bataille, Barthes reafirma a natureza essencialmente sintática do primeiro. Para isso o recurso à noção de dupla articulação foi abundantemente utilizado. 0 curioso é que, como dito acima, o "aparentemente infinito" que Barthes

7 Essa característica da língua sadeana ou da cena sadeana distancia-a da linguagem natural enquanto discurso linear (em presença) sintagmático. 
identifica no relato sadeano deve-se não ao número finito das unidades básicas como os fonemas saussurianos e as figuras sadeanas, mas, aponta ele, a um número finito de metáforas, a uma forma de operá-las, do translado de sentidos resultantes das remessas operadas de uma série de metáforas à outra. Em Sade, as combinações são de uma natureza enfadonhamente repetitivas, sempre de novo como antes. Para Barthes, Sade opera à maneira de um espírito contábil, por conta do que sua combinatória erótica "não comporta (tecnicamente) nenhuma transgressão do sexual” (1968, p. 128). Por fim, há que se admitir que o relato de Sade é tão somente uma escritura, como já dito, que só conhece insistência, não excede nunca a língua que a viabiliza; o que se pode chamar por aproximação de uma língua formal. A título de esclarecer a comparação com Bataille, Barthes reconhece na escritura desse último o que chamou de estilo: implica uma consistência, um exercício da linguagem que, pela operação metonímica aplicada às séries de unidades primeiras (sistema suporte), pode ser entendida como extraviada, infratora, o que se aproximaria de um sistema aberto de significações.

Sobre isso podemos provisoriamente apontar mais um distanciamento da linguagem de Sade com a natural, uma vez que, induzidos pela análise de Barthes, concluímos que o sistema sadeano mais se aproxima de, como dito acima, uma língua formal, isto é, um sistema fechado de sentidos, enquanto o sistema da linguagem natural seria, segundo Gaston-Granger, semi-aberto ou semifechado.

\section{Reflexões sobre a noção de língua erótica}

Passando a refletir sobre a pertinência da extrapolação da noção saussuriana de língua realizada por Barthes na caracterização da escrita de Sade, daremos continuidade afirmando que na linguagem natural a estabilidade lingüística é encontrada principalmente nos princípios de arbitrariedade e de imotivação e secundariamente nos de opositividade e valor. Isso posto, para avaliar a iniciativa de Barthes, privilegiadamente colocaremos em discussão o conceito de arbitrariedade e de imotivação, o que requer uma referência à teoria saussuriana de signo. Assim, com o arbitrário do sistema Saussure apontou para a inexistência de uma ligação motivada, de uma convenção, ou mesmo de uma identidade necessária ou interior aos componentes do signo, a saber, conceito

Rev. Filos., v. 18 n.23, p. 53-72, jul./dez. 2006 
e imagem acústica, ou ainda, significante e significado. Lembremos que essa definição proporcionou-lhe a possibilidade de explicitar a natureza da constituição, sustentação e autonomia do sistema lingüístico.

Dessa forma, o signo lingüístico definido em sua arbitrariedade e conseqüentemente em sua imotivação é pensado como composto a partir de séries distintas, isto é, tanto a série dos significantes quanto a dos significados, em quase todas as circunstâncias, nada apresenta de identidade prévia, são por assim dizer exteriores uma à outra, apenas se encontram por força e atuação exterior do sistema da língua que as associa, vale dizer, que funda o signo. Isso posto, será instrumentalizado doravante o conceito de opositividade que é derivado do de arbitrariedade. Tal conceito decorre justamente, como estamos vendo, da ausência de positividade em cada um dos termos envolvidos na composição do signo lingüístico. Em Saussure é o sistema que constitui o signo, que o define, sendo esse fruto ou conseqüência da ação autônoma da língua que atua promovendo uma relação, uma cooperação entre partes, uma composição por negatividade. Para a exploração de tal conceito recorreremos aos argumentos de Giles Gaston-Granger, como se segue.

Comecemos afirmando que a atividade científica para ele consiste na produção de modelos, um deles, que chamou semiótico visa à produção de sistemas significantes ou quase-modelos, que foi exclusivamente concebido para os fatos humanos. Nesse modelo aparecem elementos heterogêneos e níveis ou planos diversos de estruturação. Nesse caso podemos dizer que a linguagem natural admite o modelo semiótico, que apresenta não apenas uma articulação sintática, mas também semântica. Nesse caso a modelização não supõe uma mesma superfície abstrata na qual todos os acontecimentos possam realizar-se. Em verdade, supõe uma superposição de simbolismos distintos que impossibilita a formalização completa. A partir da exposição desse modelo, conceitos derivados como dupla articulação e sistema suporte voltam a demandar explicitações.

Para exemplificar, consideremos o caso da linguagem natural que em seu sistema de primeira articulação, o dos monemas, vigoram as referências extralingüísticas, ausentes no sistema suporte, o fonemático ou segunda articulação. A organização monemática, enquanto nível superior de articulação, apresenta-se, como dito, carregada de referências extralingüísticas, o que caracteriza uma superposição de simbolismos distintos. Há aqui uma perspectiva fecunda para 
investigar a natureza da língua erótica de Sade que pode ser expressa na seguinte indagação: ela apresentaria uma dupla articulação com sistema suporte sintático?

Tais conceitos que Granger toma emprestado da lingüística saussuriana definindo uma linguagem ou um sistema simbólico segundo o padrão de uma dupla articulação será de grande valia no momento em que empreendermos a análise da escritura de Sade, pois desta característica, isto é, da presença ou ausência das tais articulações, decorre a possibilidade de se pensar sua sistematização, e em especial da propriedade da postulação feita por Barthes. Sua consideração adicionalmente nos permitirá melhor compreender a possibilidade de autonomia e imotivação do código erótico, pois lembremos que Granger partiu da consideração de que o fato humano ou fato semiológico, diferentemente do fato natural, encontra-se inserido em um contexto valorizado, envolto, por exemplo, em ideologias e apresenta, por isso, significações, nunca sendo composto por dados ou elementos neutros ou insignificantes; essenciais justamente para a autonomia e imotivação do sistema. Em acréscimo, Granger chamou, em sua obra Filosofia do estilo, de 1968, essa organização anterior já provida de sentido de protocientífica. Essa poderia ser reconhecida como um sistema bruto de significações que, de posse dele, caberia ao cientista sobrepor-lhe um modelo crescentemente formal de explicação. Essa seria sua especificidade, uma articulação do sintático sobre o semântico.

Atentemos assim ao tipo de modelo semiótico que visa à produção de sistemas significantes ou quase-modelos, este concebido exclusivamente para os fatos humanos, uma vez que admite e comporta vários planos de estruturação. A título de ilustração, seria o tipo de modelização que, segundo Granger, Saussure teria concebido para a linguagem natural, que apresenta um sistema suporte, o fonemático, e uma articulação superior, a monemática, sendo o primeiro sintático e o segundo semântico.

Segundo esse ponto de vista, a língua, no sentido saussuriano, seria o sistema que num primeiro momento articula um conjunto de significantes por meio de relações paradigmáticas e sintagmáticas, como dito acima, passíveis de serem organizados sintaticamente, isto é, organizados com exclusividade e reciprocidade, o que equivale à organização fonemática. A partir desta para a articulação seguinte, a

Rev. Filos., v. 18 n.23, p. 53-72, jul./dez. 2006 
monemática, o isolamento desaparece e os reenvios semânticos vividos deixam de ser inteiramente suprimíveis. Isso é o bastante para evidenciar o limite da formalização da linguagem natural.

Seguindo essa concepção de linguagem, podemos começar a refletir agora sobre como conceber as operações da chamada língua erótica. Investigar de que articulações é dotada, se apresenta uma dupla articulação e um sistema suporte sintático como a linguagem natural. Da resposta a essas questões podemos avaliar sua natureza. Resta saber se o código erótico sadeano com seu repertório de posturas, como indicado por Barthes, pode pleitear a característica de sistema suporte, a exemplo dos fonemas da linguagem natural. Em outros termos, estamos investigando a possibilidade de que o reconhecimento de uma monotonia das posturas, já que foi admitido haver um número reduzido delas, seja suficiente para que identifiquemos nelas um repertório básico, uma articulação de base, a exemplo da observada na linguagem natural. Por conta disso, apresentaremos com maior número de detalhes o inventário de posturas sugerido por Barthes como: 0 exame da vítima; interrogatório; blasfêmia; laço de família (incesto); posição social; sujeira; feiura; estados fisiológicos etc., todos identificados com a noção de fonema.

Comecemos pelo exame da vítima. No interior desse enquadramento, destaquemos a prática de esconder escrupulosamente o sexo da mulher; sobre isso diz Barthes, "Sade pede um contra-strip-tease" (1971, p. 115); dessa forma subverte desfigurando o código ou a expectativa de imoralidade sem destruí-lo. Ele reconhece que o jogo simultâneo do mostrar e esconder permite identificar na mulher um "espaço" paradigmático que permite ao libertino/lingüista uma margem de operações. Quanto às posturas beleza e feiura, nunca dão conta da totalidade do corpo descrito por Sade. Este é sempre despedaçado, diz Barthes, "para mostrar um corpo, é preciso deslocá-lo, refractálo na metonímica de sua roupa, ou reduzi-lo a uma de suas partes..." (1971, p. 119). Dessa forma, a beleza é pensada como classe, partes do corpo, individualidades, elementos do corpo que se destacam, como pênis, ânus, nádegas, esperma etc., alternados, agregados ou isolados. A graça do corpo é a parcialidade da descrição que comporta, é decorrência da maneira alternada como cada uma de suas partes é iluminada, designada pela descrição que promove um recorte ilimitado, um fraseado infinito. 
Na identificação da estrutura do prazer com a estrutura da linguagem $^{8}$, Barthes apresenta mais uma postura/fonema, a posição social, entendida como "a diferença de classe: os libertinos opostos aos agentes; as ricas aventureiras, aos pobres pescadores" (1971, p. 120). Nos contos de Sade, as relações entre classes sociais são taxativas; explicitam uma oposição radical entre exploradores e explorados, isso na forma de um modelo recorrente: os libertinos quase sempre oriundos da aristocracia, os demais membros do subproletariado urbano e/ou servos de feudos remanescentes. Ao reconhecer a presença sempre constante de uma divisão social no interior da orgia Barthes, ao descrever as relações entre seus participantes, avança na analogia com a linguagem natural apontando para o que chamou de saturação ou catálise de toda extensão dos corpos, uma ocupação simultânea de todos os lugares de prazer do corpo. Diz ele que essa é igualmente a lógica da construção da frase, pois ela...

...É também um corpo que é preciso catalisar preenchendo todos os lugares primeiros (sujeito-verbo-complemento) com expansões, incisas, subordinadas, determinantes; certo que essa saturação é utópica, pois nada permite (estruturalmente) terminar uma frase: é sempre possível acrescentar-lhe um elemento... (1971, p. 121)

Igualmente, Sade não esgota a combinatória das unidades, não pode fechar o corpo erótico, o inventário de lugares sempre pode ser ampliado, sempre uma demanda suplementar pode ser atendida mediante novas articulações, novas operações combinatórias; pode-se dispor de todos os orifícios do corpo e, se for necessário, criar outros para a continuidade do "discurso".

O emprego das noções de dupla articulação e da postura como sistema suporte segue apoiado em mais um exemplo, os laços de famí-

8 Avançando nessa identificação, Barthes afirma que "a prática libidinosa em Sade é um verdadeiro texto - de maneira que, a respeito dele, é preciso falar de pornografia, o que quer dizer: não o discurso que se tem acerca dos comportamentos amorosos, mas esse tecido de figuras eróticas, recortadas e combinadas como as figuras eróticas do discurso escrito. Encontram-se então, nas cenas de amor, configurações de personagens, seqüências de ações, formalmente análogas aos "ornamentos" repertoriados e nomeados pela retórica clássica” (1971, p. 124). Segue na mesma página a exposição de exemplos de emprego de figuras de retórica como a metáfora, o assíndeto e o anacoluto.

Rev. Filos., v. 18 n.23, p. 53-72, jul./dez. 2006 
lia. Por conta disso define a família como "um campo lexical" (1971, p. 128), cuja característica é a de permitir a transgressão da distinção que habitualmente se atribui a cada membro da família. Em Sade, uma pessoa ou um membro da família (um significado) pode receber vários significantes (pode ocupar ao mesmo tempo os lugares de filho, neto, sobrinho, genro etc.); opera uma combinação, uma rearticulação "da rede dos laços nominativos...sobre os quais ele (o libertino) faz apoiar-se operações sintáticas" (1971, p. 128). Para isso é necessário e suficiente que ele promova uma transgressão da "regra semântica" da estrutura familiar pela via da prática do incesto, que embaralha, rearticula e multiplica os laços familiares. Uma prática entendida como contrária à natureza configura-se, nessa ótica, numa contralinguagem, que permite o gozo de uma permanente invenção, de um texto que não se exaure nunca. Barthes oferece um exemplo extraído de Sade sem citar fonte: "conta que conheceu um homem que fodeu três filhos que tivera com sua mãe, dentre os quais havia uma moça que ele fizera casar-se com o seu filho, de modo que, ao fodê-la, fodia a irmã, a filha e a nora, e obrigava o filho a foder a irmã e a sogra" (1971, p. 128-9).

Em última instância, esses exemplos de posturas, somados a outros aqui omitidos, constituem, em nosso entendimento, um repertório que somente pode com muita licença ser chamado de básico que permita uma organização sintática, não podendo assim ser identificado com o conjunto das articulações sintáticas da linguagem natural, as fonemáticas. Os "fonemas" sadianos, como vimos, não correspondem a tal arranjo, pois neles os elementos tomados como unidades mínimas possuem já valor, significados anteriores, positividade portanto. Desse modo concluímos, contrariando Barthes, pela ausência, na articulação sadeana, de um léxico básico e finito (ainda que artificialmente reduzido) e muito menos sintático, a exemplo do sistema suporte identificado na base da constituição da linguagem natural. Entendemos ainda que toda matériaprima utilizada para compor a articulação de base da língua erótica é inesgotável, além de ser plenamente significativa antes de sua inserção no sistema que participa, contribuindo tão somente com um ou alguns dos aspectos de seu, chamemos com Granger, proto-significado. Doravante será aprofundada essa noção recorrendo ao conceito de mito contemporâneo extraído de uma das obras de análise semiológica chamada Mitologias de Barthes.

Rev. Filos., v. 18 n.23, p. 53-72, jul./dez. 2006 
Como anunciado, recorreremos ao conceito de mito contemporâneo de Barthes, apresentado em Mitologias, de 1957, visando ampliar a compreensão da identificação realizada por ele. Vale investigar em que medida essa noção, igualmente apoiada na de dupla articulação pode auxiliar no propósito desse artigo. Para tanto vale anunciar um aspecto da natureza básica do signo mítico: seu significante já é signo em outra cadeia ou ordem simbólica. Em razão disso, o signo mítico expresso em um cartaz publicitário, por exemplo, recebeu de Barthes, como visto, a denominação de sistema simbólico de segunda ordem.

Queremos dizer que pelo fato de a língua sadeana não poder ser reconhecida como dotada de um sistema suporte ou uma base sintática, uma vez que repousa desde sempre sobre uma base semântica, isto é, constituída por elementos já dotados de significação, muito oportunamente se ajusta à estrutura de signo mítico de Barthes. Esperamos assim poder extrair daqui comparações férteis para a compreensão da estrutura do código erótico de Sade. Contudo, antes disso, devemos apresentar com mais detalhes os argumentos de Barthes relativos ao que chamou de signo mítico que abrange, como dito, desde uma foto jornalística, passando por uma peça publicitária, um cartaz, um traje, um filme, um simples gesto, uma maneira de se vestir etc..

Lembremos que o propósito de Barthes sempre foi o de captar ou descrever significações, ou ainda, sistemas geradores de signos. Assim definiu o mito contemporâneo, mantendo-se fiel ao vocabulário saussuriano, como uma fala, uma fala mítica, como um modo de geração de significações que tem como objetivo instituir intencionalmente, embora muitas vezes de forma dissimulada, uma comunicação, uma mensagem. No entanto, o que faz do mito algo especial no universo das diferentes linguagens é que potencialmente tudo pode ser mito, isto é, qualquer substância, qualquer objeto do mundo pode ser tomado como elemento para a composição do mito e conseqüentemente funcionar como parte constitutiva de tal significação, veiculando uma mensagem pretendida.

Com isso podemos dizer que o suporte para essa linguagem pode ser "o discurso escrito, assim como a fotografia, o cinema, a reportagem, o esporte, os espetáculos, a publicidade..." (Barthes, 1957, p. 132). Isso quer dizer que de um modo geral toda e qualquer matéria pode ser adotada com o propósito de promover e sustentar a significação mítica, desde que mantenha um vínculo entre o representante e 0 representado que seja suficiente para instituir um tráfego conveniente

Rev. Filos., v. 18 n.23, p. 53-72, jul./dez. 2006 
entre eles. Dessa forma, na concepção de Barthes, a fala ou mensagem mítica é composta "por uma matéria já trabalhada em vista de uma comunicação apropriada" (1957, p. 132).

Aprofundando e recordando a noção de significante na significação mítica, é bom esclarecer que este é, segundo Barthes, simultaneamente signo no seu primeiro sistema, de onde derivou, e forma ou significante no segundo sistema, o do mito, onde será locado. Assim, enquanto matéria-prima, já oferecia uma leitura interpretativa, já possuía uma riqueza, já era um material eleito como adequado para integrar uma nova significação. Com isso Barthes quer dizer que havia conteúdo significativo nesse primeiro sistema do qual o operador de mitos dispõe como matéria-prima para inseri-lo no novo contexto por ele desejado. Dessa forma apontamos para uma base semântica própria desse primeiro sistema que "já está completo, postula um saber, um passado, uma memória, uma ordem comparativa de fatos, de idéias, de decisões” (1957, p. 139).

Dessa forma, a exemplo da significação mítica de Barthes, podemos dizer que as articulações do sistema sadeano são construídas a partir de uma cadeia semiológica que existia já antes de seus desdobramentos. Seria, como diz Barthes, "um sistema semiológico segundo" (1957, p. 136). Agora é possível dizer que, por analogia, tanto no mito contemporâneo como definido por Barthes, como no código erótico, como concebido por Sade, existem dois sistemas semiológicos em ação. Há assim como conteúdo desse processo o que Barthes chamou de linguagem objeto, justamente a linguagem que funciona como suporte; não o sintático da linguagem natural acima referido, mas um puramente semântico do qual o mitólogo se serve para criar significações - e que Sade se valeu para criar sua língua erótica. Quanto a esse sistema segundo que é sobreposto, Barthes deu-lhe o nome de metalinguagem, na medida em que é entendido como uma espécie de segunda articulação.

Não deixemos de esclarecer que o processo de significação dos mitos da imprensa, por exemplo, implica numa deformação, como visto, em grande parte das vezes intencional, consciente e motivada, embora em outras tantas não. Acrescentemos que a análise do mito que é tarefa do semiólogo ou mitólogo deve permitir nesses casos o esclarecimento de uma ideologia implícita ou não, consciente e motivada ou não, justamente a que se encontra por trás do seu criador, este responsável ou responsabilizado pela sua deformação, isto é, a deformação imposta pode ocorrer para atender às suas exigências, por exemplo, de mercado ou mesmo pessoais. 
O fato é que Barthes tomou os diferentes sistemas simbólicos que servem ao mito como compartilhando e apresentando "comportamentos" e "esquemas" do signo lingüístico. Nesta concepção, a linguagem-objeto que serve ao mito estaria sendo considerada a partir da teoria lingüística, do signo lingüístico, e não por uma teoria do signo em geral. A prática barthesiana parece-nos estar assim "mesclando", sob a mesma teoria dos signos, aqueles que são naturalmente imotivados (os lingüísticos) e os motivados (os mitos contemporâneos). Muito provavelmente por ocasião desta mescla, já em Elementos de semiologia, de 1964, Barthes anuncia e posteriormente em Sistema da moda, de 1967, adota a consideração de que a teoria do signo lingüístico aplica-se à análise semiológica de diferentes sistemas desde que estes estejam repassados pela linguagem natural. Com isso e por isso, passa a realizar análises dos discursos proferidos na descrição lingüística de sistemas simbólicos em geral. Muito embora permaneça impregnado de inspiração saussuriana, Barthes, com a concepção acima exposta, engendra sua própria e particular teoria semiológica.

Julgamos procedente inserir aqui uma crítica feita por Granger no capítulo V da obra Langage et epistemologie, de 1979, onde considerou abusiva a aplicação da noção de língua e seus derivados a propósito de qualquer sistema simbólico, de qualquer fato cultural, pois em verdade admite que tais fatos possam existir enquanto sistema, mas alerta que seus signos nem por isso podem sempre ser chamados saussurianos. Isto pelo fato de o valor dos signos não ser neles só negativo ou opositivo, como no signo lingüístico. Reconhece Granger que, muitas vezes, as propriedades de uma língua são atribuídas sem problemas a sistemas onde não se aplicam dessa forma, isto pelo simples fato de diferentes sistemas serem tomados como linguagens, em função do que se está, por equívoco ou precipitação, emprestando a diferentes sistemas a forma de uma língua. Trata-se justamente do alerta que procuramos fazer relativamente à particular concepção e prática semiológica de Barthes, inclusive quando atribui a Sade a noção de logoteta.

Por isso a crítica de Granger parece-nos pertinente, pois realça a impropriedade de se tomar a linguagem natural como protótipo de sistemas simbólicos em geral, ainda que estejamos autorizados a tomá-la como sistema simbólico por excelência, justamente em virtude de sua complexidade estrutural, já apontada por Saussure e não por apresentar traços elementares e fundamentais que compreendam toda ordem simbólica.

Rev. Filos., v. 18 n.23, p. 53-72, jul./dez. 2006 
Após termos criticado a intenção de Barthes de extrair da ciência lingüística um instrumental suficientemente válido para o exercício da pesquisa semiológica, reconheçamos que o recurso aos esquemas lingüísticos teve por objetivo permitir análises bem mais sistemáticas. Ainda a propósito do recurso que Barthes fez a tais esquemas vale verificar os impasses e as justificativas de sua proposta de estruturação semiológica a partir do binômio língua/fala.

Nossa intenção nesta investigação é a de saber se a utilização que fez dos conceitos lingüísticos como, entre outros, língua/fala não passaria de uma ornamentação de sua prática de escrita sobre moda, literatura, publicidade entre outras coisas. $\mathrm{O}$ recurso lingüístico foi utilizado como se reproduzisse uma possível estrutura binária dos sistemas que descreve. Tal conceito reconhecidamente presente na linguagem natural é apontado por Barthes como igualmente presente na moda, na alimentação, enfim, nos diferentes "sistemas" que a linguagem natural descreve.

Assim podemos criticar Barthes por ter aplicado, por exemplo, em Sistema da moda impropriamente a noção de língua. Sabemos que um sistema, como o referido, que é elaborado a partir de um centro de decisão (o que no caso de Sade aproxima sua escrita de uma linguagem artificial) jamais poderia ser assimilado à noção saussuriana de sistema autônomo. Igualmente, podemos dizer que a "língua erótica" construída por Sade é justamente marcada pelo aspecto da motivação e de um tipo de convencionalismo, características estas que negam todo o princípio de autonomia do sistema proposto por Saussure.

Contudo, utilizações conceituais deste tipo pareceriam reduções simplórias da parte de Barthes se não houvesse nele o propósito de garantir o rigor dos conceitos transpostos de um sistema para outro. Felizmente Barthes refere-se, por exemplo, ao par língua/fala, como sendo um instrumento ou uma categoria que se pensaria ser suficientemente geral para permitir e viabilizar a preparação da pesquisa semiológica em diferentes campos. Com isso ele nos faz ver que a reunião destes conceitos não garante necessariamente sua subsistência no decurso da pesquisa. De fato Barthes mostra-nos que nem mesmo a semiologia deve ou deverá sempre seguir estritamente o mesmo modelo, com o que reconhece que um possível "desvio" ou uma possível "adaptação" das prescrições saussurianas não corresponderia a um abandono da construção da ciência semiológica, nem mesmo motivo para alterar-lhe o nome.

Rev. Filos., v. 18 n.23, p. 53-72, jul./dez. 2006 
Segundo estas últimas argumentações que aparecem claramente já nos primeiros capítulos dos Elementos de semiologia, conceitos do tipo língua/fala, significante/significado, entre outros, estariam apenas a serviço da criação de um princípio de classificação que permitiria a introdução de uma ordem inicial na massa diversificada dos fatos culturais, podendo tais princípios ordenadores permanecerem sempre provisórios ou substituíveis. Ao postular a existência de uma categoria geral língua e fala extensiva a todos os sistemas de significação ele também reconhece que "na falta de algo melhor, conservaremos aqui os termos língua e fala, mesmo que não se aplicarem a comunicações cuja substância não seja verbal" (BARTHES, 1964, p. 28). Presenciamos nessa citação uma nítida declaração de independência intelectual, conceitual e metodológica. Barthes manteve sempre a marca de quem estava iniciando, criando propriamente uma atividade intelectual. Continuando com cautela diz ainda que...

...Vimos que a separação entre língua e fala constitui o essencial da análise lingüística; seria vão, pois, propor logo de saída esta separação para sistema de objetos, imagens ou comportamentos que ainda não foram estudados sob um ponto de vista semântico. Podemos, somente para alguns dos sistemas propostos, prever que certas classes de fatos pertencerão à categoria língua e outros à categoria fala, dizendo logo que, nesta passagem semiológica, a distinção saussuriana está exposta a modificações, as quais cumprirá precisamente observar (BARTHES, 1964, p. 28).

Dessa forma, com vistas nas justificativas acima apresentadas, parece ficar claro que Barthes não estava e nem nunca esteve incorrendo em uma precipitação ou ingenuidade, antes esteve sempre consciente das dificuldades teóricas de postular uma prática semiológica onde conceitos são por ora utilizados e não construídos. No entanto, não por ignorar as incompatibilidades, mas por acreditar nas possibilidades, manteve por algum tempo e algumas obras o "sonho" de poder analisar estruturalmente fatos sociais. Análise que, respaldada na "cientificidade" do método semiológico adotado, estaria, por assim dizer, conferida de autenticidade, podendo com segurança explicitar códigos, os códigos que respaldariam as ideologias da sociedade burguesa de sua época, da qual sempre foi crítico ferrenho.

Para concluir, lembremos que o "sonho" a que nos referimos, mantido até Sistema da Moda, acabou por ser deixado de lado por Bar-

Rev. Filos., v. 18 n.23, p. 53-72, jul./dez. 2006 
thes, recusando o estruturalismo e distanciando-se da lingüística e de seus conceitos. A fase pós-estruturalista de Barthes merece de nossa parte especial atenção por constituir uma nova perspectiva semiológica, mas demandará um outro espaço e oportunidade.

\section{Referências}

BARTHES, R. Sade, Fourier, Loyola. São Paulo, SP: Brasiliense, 1971.

. A metáfora do olho. In:BATAILIE, Georges. História do olho. São Paulo, SP: Cosac Naify, 2003.

. Elementos de semiologia. São Paulo, SP: Cultrix, 1964.

. Mitologias. São Paulo, SP: Difel, 1957.

BATAILLE, G. O erotismo. São Paulo, SP: Arx, 2004.

. História do olho. São Paulo, SP: Cosac Naify, 2003.

BOCCA, F.V. Roland Barthes: um semiólogo nômade. Revista de Filosofia, Curitiba, v. 15, n. 17, 2003.

. Breve análise do estatuto de cientificidade da Interpretação de Sonhos, de Sigmund Freud, na perspectiva semiológica de Giles-Gaston Granger. Revista de Filosofia, Curitiba, v. 14, n.15, 2002.

GRANGER, G. G. Langage et epistemologie. Paris: Klincksieck, 1979.

. Pensée formele et sciences de l'homme. Paris: Aubier-Montaigne, 1965.

. Filosofia do estilo. São Paulo, SP: Perspectiva, 1968. $27-49,1969$.

. Proposições para um positivismo. DISCURSO, São Paulo, n. l, p.

SAUSSURE, F. Curso de lingüística geral. São Paulo, SP: Cultrix, 1915.

Recebido em/Received in: 08/06/2006 Aprovado em/Approved in: 10/07/2006 